\title{
Universal Credit, Gender and Structural Abuse
}

\begin{tabular}{|r|l|}
\hline Journal: & The Journal of Adult Protection \\
\hline Manuscript ID & JAP-05-2021-0018.R2 \\
\hline Manuscript Type: & Research Paper \\
\hline Keywords: & $\begin{array}{l}\text { Domestic violence and abuse, structural abuse, Universal Credit, COVID- } \\
19, \text { Welfare reform, support workers }\end{array}$ \\
\hline
\end{tabular}

\section{SCHOLARONE $^{\text {m }}$ \\ Manuscripts}




\title{
Universal Credit, Gender and Structural Abuse
}

\section{Jonathan Parker and Kelly Veasey}

\begin{abstract}
Purpose

Joint couple payments under Universal Credit tend to privilege male partners, which may entrap women in abusive relationships, foster poverty, and are indicative of gendered structural abuse.

\section{Design/methodology/approach}

Through a critical review of the literature and qualitative interviews with third sector support workers we explore the impacts that Universal Credit has on women, especially those in abusive partnerships.

\section{Findings}

Current welfare processes reinforce patriarchal assumptions and are indicative of the structural abuse of women. This has increased during the lockdowns imposed to tackle COVID-19.

\section{Originality}

This paper argues that there needs to be a wider a recognition of gender power relations and the concept of structural abuse in policy formation and implementation.

\section{Practical implications}


Changes are needed in the ways in which welfare benefits are disbursed. Gendered structural abuses should be explicitly considered when working with women who experience domestic violence and abuse.

\author{
Key words \\ Domestic violence and abuse, structural abuse, Universal Credit, COVID-19
}

\title{
Universal Credit, Gender and Structural Abuse
}

\section{Introduction}

Universal Credit (UC) payments for couples are made as joint payments into the nominated bank account of one of the claimants named as the 'main claimant'. In heterosexual couples, normative assumptions of gender relations mean that this 'main claimant' is often the male partner and the UC system will often set this as the default (Millar and Bennett, 2016). Not only is this approach inherently sexist but also it has the practical outcome of disproportionately affecting women by lessening their access to income and decreasing their economic autonomy (Millar, 2018).

In earlier work, we considered the importance of recognising structural abuse and the treatment of older people in care homes (Parker, 2021). Structural abuse, however, can affect anyone as a result of shared social characteristics with people who are marginalised by assumed, often unspoken, social mores. Systemic structural abuse may go unchecked and unnoticed through policies, practices and perceptions that become embedded in the psyche of the general population, which may, in turn, allow 
governments to escape responsibility for ensuring the adequate and appropriate treatment of all. Structural oppressions are part of the everyday experience, reproduced through social interactions and reinforced by interactions with those institutions carrying social power. Structural abuse intersects with gender, race, and class relations and is embedded within socio-economic, health, disability-focused, and age-related elements of society (Crenshaw, 1989; Parker and Ashencaen Crabtree, 2018; McVey et al., 2020; Parker, 2021). These dominant and unspoken assumptions influence the ways in which social welfare and care policies are developed, delivered, and the eligibility criteria are used to apportion care.

In this paper, we consider the perceptions of third sector and voluntary support workers for homeless people; to understand the ways in which increased welfare conditionality and UC processes have affected people who are homeless and at risk of homelessness. We are looking, particularly, at women and those at risk of domestic violence and abuse (DVA), and consider the unanticipated consequences of welfare reform that both increase the potential for abuse and reinforce structural gendered assumptions.

We suggest that current welfare processes reinforce patriarchal assumptions and are indicative of the structural abuse of women. These social problems have increased during COVID-19 lockdowns, with reports of DVA rising significantly (Hantrais and Letablier, 2021). We call for a change in welfare benefits disbursement, a recognition of gender power relations, and for the wider acceptance of the concept of structural 
abuse. We argue for gendered structural abuses to be explicitly considered when working with women who experience DVA.

\section{Background}

\section{Welfare, Conditionality and Universal Credit}

Welfare reform, and its attempted simplification and cost reduction, has been at the heart of United Kingdom (UK) welfare policy for decades, if not centuries (Dean, 2004; Fletcher and Wright, 2018; O’Hara, 2020). In 2009, Iain Duncan Smith outlined a vision for combining six main benefits into one, which resulted in the 2012 White Paper and Welfare Reform Act that ushered in the current UC system. From 2013, UC, replaced the UK's main working-age benefit. It combines most existing meanstested benefits and tax credits into one single system and payment for those in and out of work (Pennycook and Whittaker, 2012). It is estimated that more than six million people will be in receipt of UC by the time it is fully rolled out by the new completion date of September 2024 (UK Government, 2021). However, moving to a single system may place claimants in a more vulnerable position if something goes wrong. Without a support network that can provide the financial assistance, many recipients may face hardship (Millar, 2018; Millar and Bennett, 2016).

The changeover to monthly payments and combining of couples' finances were justified as mimicking the realities of working life, encouraging self-responsibility and easing the transition into employment. However, this demonstrated a lack of understanding of the circumstances of many claimants or the implications of monthly payments (Howard, 2018). For instance, only one in ten claimants believed this would 
improve their budgeting situation, with the majority expressing struggles to make their money last until the end of each week (Millar and Bennett, 2016).

Concerns were also raised over the introduction of work-based eligibility requirements for both members of a coupled household. While the conditionality of former benefit systems was only imposed on couples where both members were able to work and had no dependent children, the new welfare regime requires updates on any changes to individual circumstances, such as illness, hours of work, and the partner who is responsible for the child(ren) (Lakhani, 2012).

The core rationale underpinning UC was to simplify the benefit system, improve incentives to take up paid work by removing the 16-hour work cap, and to make it clear that work pays while protecting claimants from poverty (Anderson, 2019; DWP, 2012; Lakhani 2012).

The welfare reform programme has seen an increase, over time, in workfare, conditionality and sanctions. Attempts to reduce the cost of welfare benefits, despite the national insurance contribution made by those in work, however, has led to a range of tactics to divert people away from welfare support. In part this has been achieved through embedding spurious notions of 'skivers and strivers', the 'deserving and undeserving' into the minds of the general population (O'Hara, 2020), and partly through more stringent eligibility criteria for unemployment benefits and a system of rules (conditionality) and penalties (sanctions). This can be viewed as the start of an 
altered status and praxis of the right to 'welfare' into the obligations of 'workfare' (Veasey and Parker, 2021; Wacquant, 2009).

Increased conditionality has introduced a system whereby claimants are routinely required to undertake certain actions and to demonstrate work-seeking behaviours in order to qualify for benefits or face sanctions and benefit withdrawal. These changes have been made by governments of every political hue and are seen to address the, unfounded, assumptions that universal benefits lead to a 'something-for-nothing' culture (O’Hara, 2020). However, intensification of behavioural conditionality, over welfare as an entitlement based on individual need, undermines the rights of social citizenship (Dwyer, 2004; Patrick, 2014), and disproportionately affects women who are more likely to manage the budgeting and essential purchasing responsibilities for households (Millar and Bennett, 2016).

\section{Sexism in the system}

The welfare state architecture was built around a conception of society based on heterosexual families that accepted, as normative, the role of the male as breadwinner and the woman as wife and mother. Thus, financial dependency was written into the social protection system (Pascall, 2012). This level of sexism may be considered discriminatory but perhaps benign in functionalist terms where two person heterosexual families are considered the backbone of society (Cheal, 2002). Such a perspective, however, fails to acknowledge the presence and the levels of domestic and intimate partner violence and abuse in families (Penhale and Parker, 2020), and the multiplicity of family forms (Cheal, 1999; Finch and Summerfield, 1999). 
Universal Credit represents one of the most radical reforms of social welfare and social protection in recent years, but continues the normative assumption of male breadwinner in control of finances. Many second earners (mostly women) have experienced a decline in socio-economic position and agency compared to the previous system, with their welfare payments becoming more reliant on their partner's income and compliance with the claimant commitment (Millar and Bennett, 2016). These UC reforms have prioritised tackling 'welfare dependency', rather than gendered economic dependencies (Bennett, 2012; FPI, 2011; Millar and Bennett, 2016).

However, the government's objective does not apply equally to all claimants. According to its Equality Impact Assessment, welfare reform's main priority is to 'encourage work at household level', the aim being to reduce the number of households where no one is working by 300,000 . However, the government admit that there may be a decrease in work incentive for second earners in couples because, when claimants enter paid work and increase their earnings, UC is withdrawn at a single taper rate for all claimants (DWP, 2011: 23; Lakhani, 2012). Consequently, there are increased financial incentives for first earners to take up paid work and decreased incentives for second earners (Anderson, 2019).

Disincentives for second earners to work are exacerbated by the restriction of financial support for claimants with dependent children to $70 \%$ of the childcare costs which is inadequate to meet the increased cost of childcare and incompatible with full-time employment, resulting in many second earners working part-time or even 
remaining unemployed (Lakhani, 2012). The introduction of UC subjects responsible carers to significant levels of conditionality and severe sanctions for non-compliance with work-related requirements. Those with preschool age children are now expected to actively look for paid work. This greatly impacts gender relations and the gendered division of labour (Orloff, 2009).

In the case of couples, both members of the couple have to agree to a separate Claimant Commitment before UC payments can be received. If one member of the couple fails to comply with his or her work-related requirements, the sanction rate is fifty per cent of the basic allowance for the couple. However, as there is only one payment, the whole family will be affected by a sanction (Millar and Bennett, 2016).

\section{Financial Abuse and Women's Economic Autonomy}

The concerns of gender and poverty within policy design are complex and intertwined (Fahmy et al., 2016). Women have historically held a disadvantageous position as citizens, defined by an exclusively masculine image of economically independent workers (Cass, 1994; Lister, 2003; Orloff, 2009). This gendered structure also devalues unpaid care work, traditionally seen as the role of women, as it impedes an individual's work-based responsibilities as a citizen (Lynch and Lyons, 2009).

Empirical evidence has demonstrated that women from more vulnerable backgrounds, including those from DVA families, are more likely to face poverty. This has been linked with the UK's regime of welfare cuts since the 2008 financial crash as well as wider cuts to tax credits and health and social care services (Fahmy et al., 2016). 
There is potential for the inbuilt sexism in the UC system to foster financial abuse in unequal and abusive relationships, as abusive partners may be enabled to control the couple's total income and limit the survivor's access to money (Fahmy and Williamson, 2018; Veasey and Parker, 2021). Although the couple can nominate a different account to have their welfare paid into, DWP will designate a payee which, in most cases, is the male partner (Fahmy and Williamson, 2018; Howard, 2018).

It may be considered important, therefore, to have the means to split the payments on grounds of domestic abuse. However, this can often place women at greater risk, given the abuser will receive a notification informing them of this request (Howard, 2018). The result is a welfare regime that, in its attempts to lessen 'welfare dependency', may be supporting 'dangerous dependencies' in DVA partnerships, (Fahmy and Williamson, 2018).

Instead of improving the socioeconomic agency of women on low-income experiencing DVA, these policies can trap women in abusive relationships. Reducing welfare dependency has unintentionally fostered a greater dependency on abusive partners, with women's only means of escape putting them at greater risk of poverty (Fahmy et al., 2016).

\section{The impact of COVID-19}

The coronavirus pandemic has resulted in a sharp increase in domestic abuse and violence incidents in the UK (Grierson, 2021), partly stemming from the effects of lockdowns, which created a degree of invisibility around and exacerbated stress in relationships (Women's Aid, 2020). Office for National Statistics (ONS) (2020) figures from March to June 2020 indicate there were 259,324 domestic abuse related 
reports to the police representing a $7 \%$ increase on the previous year and an $18 \%$ increase on 2018. While the number of reports has been rising year on year, making it difficult to link the rise with the pandemic, the largest number of reports came after the first lockdown was eased between, April and May, and suggest they came at a time women felt safer to take action. Similar increases were reported in the United States (US) (Evans et al., 2020), across Europe (Hantrais and Letablier, 2021), and elsewhere (Roesch et al., 2020).

Women's Aid (2020) reported that $78 \%$ of survivors experiencing DVA found it more difficult to take action during lockdown because of less access to housing, refuge accommodation and because abusers used lockdown restrictions to intimidate them. Whilst social protection under UC has been increased by $£ 20$ per week for families, which has cushioned the severity of the financial impact of the pandemic on many, this has, to some extent, increased the risks on women in families where DVA is an issue (Veasey and Parker, 2021). Male partner financial control remains embedded in the system, whilst the focus of social welfare has been diverted towards the pandemic and away from abuse. Also, reductions in support services for people experiencing domestic abuse, alongside decreased opportunities to leave abusive relationships and secure safe alternative accommodation, have left many women exposed to continued and heightened domestic abuse, whilst social support structures ignore their needs (Sánchez et al., 2020).
Alongside this, Banga (2020) draws attention to complexities of the UC system, delays in payments and difficulties arising from the pandemic as further hampering 
the efforts of women leaving abusive relationships. Making a UC application through a system near to collapse resulted in women losing income sources and struggling to register on the benefits system. According to Banga (2020), COVID-19 has allowed the precarious financial circumstances of women in refuges to be 'weaponised' by perpetrators.

\section{Structural abuse}

The concept of structural abuse has its roots in critical thinking in which the structures of society influence how we act, think and speak. Everyday thinking and behaviour become the norm, accepted as being the way things are or should be and ultimately becomes unquestioned. Pierre Bourdieu, the French social theorist, articulated this well in his concept of the habitus, which he describes as enduring predispositions that are structured by the way the world is experienced and which reflect back on the world to reinforce existing conditions (Bourdieu, 1977; 1994). We have seen examples of this in the everyday sexism movement initiated by Laura Bates, and latterly in the Black Lives Matter campaigns, especially after the death of George Floyd where casual and unquestioned sexism and racism lead to significant and, sometimes catastrophic consequences. When writing this paper, this was further reinforced in the debates concerning the Domestic Abuse Act 2021 (Elgot, 2021).

These dispositions are further influenced by structures. In social welfare, we recognise an interplay between the ways in which women are viewed in society, as unequal to men and dependent upon them, and the daily practices of welfare in which males represent default claimants in heterosexual couples and where DVA services, often staffed by women, are reduced and underfunded. This is evidenced in the 
language employed in official statistics of domestic abuse and violence, where the ONS describe those experiencing DVA as 'victims', whilst Women's Aid (2020) employ the less passive descriptor 'survivors'. The accepted use of language helps to reinforce everyday aspects of structural abuse. Social welfare, as we know, is designed to control the populous as much as to ease distress (Wacqunt, 2009), whilst the coercive elements of social administration reinforce normative social mores, although the structural and individual elements of society interact and influence one another (Foucault 1991; Gaventa, 2003). A shift to power based on disciplinary systems of surveillance and assessment do not need force or violence to produce conformity, as people learn to discipline themselves and behave in normative ways because of the surveillance they perceive as operating in societal structures. Structural power is not so much imposed from outside as internalized becoming the taken-forgranted understandings that influence how social services are organised at a structural level and practised at an individual level (O’Hara, 2020).

\section{Methods}

This paper comes from a broader study of the impact of conditionality on homeless people as perceived by third sector and voluntary support workers (Veasey and Parker, 2021). Interviews took place in early 2020 before the COVID-19 lockdowns. Whilst we may surmise that the situation has not improved, we cannot say how it has changed for the support workers in our study, but the bleak findings in respect of prepandemic structural abuse of people experiencing domestic abuse and violence has resonance with the subsequent COVID-19 situation.

The study explored the 'life worlds' of a small group of eight paid and voluntary support workers for homeless people in three locations in the South West and South East of England through semi-structured interviews. This group is frequently ignored in research as they are not part of the formal or statutory sector of housing and social 
welfare and support workers, but they often have both deep and personal knowledge of those homeless people they are helping and are the first line of support for them.

The small sample size, number and geographical setting of locations are acknowledged as limitations. However, the rich qualitative data gathered provides a unique perspective on the UC debate concerning homelessness and in respect of the impact on women experiencing domestic abuse and violence.

Interviews were audio-recorded, transcribed and a familiarity with the transcripts was built over multiple readings. Themes and comments characteristic of the support workers' perceptions were noted and emergent themes and topics developed from these (Smith et al., 2009). The themes and subthemes were compared and contrasted to identify interconnections and a picture was built to illustrate the impact of UC on women experiencing domestic abuse and violence.

Ethical permission for the study was gained in accordance with Bournemouth University's Research Ethics Code of Practice: Policy and Procedure (Checklist ID: 28258). The anonymity of the participants and their organisations, names and places of work is preserved throughout.

\section{Findings and discussion}

Welfare, Conditionality and Universal Credit 
Despite efforts to simplify the benefit system, respondents agreed there was a lack of awareness at government level of the structural consequences for women's autonomy and the potential consequences for fostering unequal and abusive relationships. These concerns were well captured by respondent 4 :

I think the government should find out what is actually happening on the ground and maybe listen to those on the ground a bit more, because I think a lot of people before Universal Credit has been rolled out, said there would be [...] these kind of problems have happened, if they had listened, maybe they could have ironed it out a bit more. [...] Universal Credit is a bad thing, we haven't seen the worst yet, unfortunately.

For this respondent, the government has seemingly designed a welfare system based on pre-conceived notions of 'skivers and strivers' that justified increased conditionality and cuts to public expenditure (Cheetham et al., 2019; O'Hara, 2020). This demonstrated a lack of consideration for negative implications, such as making lump sum monthly payments to claimants who struggle with budgeting and increased economic dependency on the household's primary earner (Howard, 2018; Millar and Bennett, 2016).

\section{Sexism in the system}

As Stephenson (2017) and Millar and Bennett (2016) note, the nomination of a 'main claimant', joint payments, and earnings thresholds reinforce the regressive ideology of the male breadwinner model. Respondent one recognised the gendered inequality of this:

Some people when they have had a single claim, or separate claims, come together, it does get a bit messed up. I think people, maybe do lose out 
financially on doing that, especially, if they have said they have split up with their missus, or husband, they end up having no money, as it takes time to adjust the claims again.

The respondent highlights how the joint payment system has shifted the dependency of many second earners from the state to their partners. This has led to a significant reduction in the socio-economic agency of women (Bennett, 2012; Millar and Bennett, 2016). Additionally, if the primary earner is sanctioned for failure to comply with their work-based requirements, this has a knock-on affect on the income of the second earner (Millar and Bennett, 2016). Respondent five agreed as they went on to elaborate the unquestioned sexism of assuming a male breadwinner role as normative: I had a couple who were over in the hospital and had been referred to us. The husband was too poorly to come out of the hospital [...] So, the wife came over to set up the account, I say the account, I thought it was going to be separate accounts, but it is not. So, we set up her account, said that she had a partner who also needed account, then her account just went, you couldn't access her account, without accessing his account. [...]it defaulted to him, to the man, even though she was the first person, that to me is discriminatory. How dare they put the account in his name and under his control and not her? I mean I am shocked that nobody has challenged that previously.

The respondent identifies the discriminatory gender practices embedded within the UC system (Cheal, 2002; Pascall, 2012). In many UC couple claims, the man has an element of control over their partner's finances, which is further enabled by the requirement that both members must agree if one wishes to separate the payments 
(Millar and Bennett, 2016). Respondent five elaborates further how the design of UC fails to acknowledge how this is likely to impact on DVA relationships:

So, then what happens in a coercive and controlling relationship where whoever the main account holder is, and it is always the man it seems to be by default? What if he is coercive and controlling and financially controlling her?

From out of the sexist framework on which UC has been built is the potential to foster greater financial abuse within unequal and abusive relationships. As the abuser is afforded greater control over the household's income, they can limit the survivor's access to the money that they require to escape those circumstances (Fahmy and Williamson, 2018; Veasey and Parker, 2021). This demonstrates a lack of understanding at the governmental level of the presence and prevalence of DVA partnerships as a systemic problem and tool of patriarchal oppression that requires a systemic solution that addresses women's socioeconomic and cultural position and represents a safeguarding issue because of the potential for normalising gendered inequalities and resulting social, as well as other, violence against women (Krishnadas and Taha, 2020; Penhale and Parker, 2020).

\section{Financial Abuse and Women's Economic Autonomy}

Previous research has found that those in DVA partnerships were more likely to face economic hardships, have a lower household income, and be in receipt of welfare. Victims of abuse are less likely to actively participate in the labour market and, due to their financial insecurity, can find themselves trapped in these relationships by the threat of substantial financial penalties (Fahmy et al., 2016). The continuous regime 
of welfare cuts since the 2008 financial crisis is set to have worsened this, with women being disproportionately impacted (Shaver, 2019).

Respondent six elaborated on the impact where domestic abuse and violence is an issue when asked who seemed to be most affected by the UC system. This response reflected the entrenched aspects of gender differentials in work, welfare and financial systems indicative of structural discrimination and potential reinforcement of abuse:

$$
\begin{aligned}
& \text { "I had a couple, one of them with learning difficulties, he had complete } \\
& \text { control of all of the money, she was given a pittance. I mean she eventually left } \\
& \text { him, therefore, extricating herself from that joint Universal Credit account, it } \\
& \text { takes time, he has still got control of the money, she has got no financial } \\
& \text { freedom, because it is the joint account that it is being paid into [...] it is } \\
& \text { discrimination in my view." }
\end{aligned}
$$

This links back to the aforementioned link between the introduction of joint couple payments with an increased reinforcement of 'dangerous dependencies' on an abusive partner within DVA arrangements (Fahmy and Williamson, 2018). The UC system is constantly underlining the responsibility of individuals to conform to their work and job-seeking obligations, while failure to do so results in sanctions for the joint couple claim. As a result, many women find themselves trapped in abusive relationships, perpetuated by the ever-present risk of poverty and/or homelessness for survivors who want to escape (Fahmy et al., 2016; Veasey and Parker, 2021). This requires a policy shift that recognises and addresses these issues.

Respondent seven adds to this, recognising the links with substance abuse:

It causes problems, if you have got someone who is drug or alcohol dependent or is abusive or has an addiction [...] and isn't as good with their money. If it 
is a joint thing, it can really affect where that money and where that household goes. But if it was kept separate and the other partner was really good with money, at least there would be something to pay the bills [...] If it is just their money then that's their choice, but when it is joint and they are using both, you know it is all in one place, one pot, then you are going to get yourselves into problems and again you are going to impact the other person and if you bring children into, oh my goodness.

These responses illustrate the concerns surrounding the impact of practices, such as the joint couple payments, of the UC welfare reform on financial abuse in DVA partnerships, as abusive partners are afforded greater monetary control (Fahmy and Williamson, 2018). As Davidge et al. (2020) explain, this comes at a time where domestic abuse support services have been impacted by a lack of funding due to the government's punitive austerity measures.

According to Howard and Skipp (2015), this lack of economic support from the welfare state has made it increasingly challenging for survivors of domestic abuse to financially liberate themselves from their abusers, leading to an increased risk of poverty or homelessness post-separation and demanding change in current welfare and housing practices alongside a role for safeguarding. Which is, of course, everybody's business.

\section{The impact of COVID-19}

In many cases, abusive partners try to control or diminish the victim's contact with others, with isolation and surveillance acting as a form of control. Usually, however, the victim is often able to receive some reprieve from their home lives through the support offered by institutions, such as churches, schools, and libraries (Campbell, 
2020). The lockdown restrictions have emphasised social distancing and isolation measures as vital steps to reducing the spread of the COVID-19 virus which makes this more difficult for those in DVA partnerships (van Gelder et al., 2020).

Respondent six alluded to this:

"Couples in a way, because if one of them works, the other one hardly ends up with any money. If there is an abusive couple and the partner is abusive and they're financially abusing their partner, the partner will end up with no money. I mean I have a couple at the moment where he earns and they were on Universal Credit while he was out of work, going into her account, soon as he starts work he is getting his wages, and most of the Universal Credit is cut, so she gets hardly anything, and he spends his money how he wants to, and she is left with loads of bills piling up."

While not specifically linked to the pandemic, accounts like this are likely to be exacerbated by COVID-19. Extended restrictions on social contact and closures of workplaces have reduced income for many households and compounded psychological and financial stress that can trigger negative coping mechanisms, such as alcohol abuse. These factors contribute to increased risks of abusive, controlling, and violent behaviours within families (Catalá-Miñana et al., 2017; van Gelder et al. 2020).

Compared to the average figures before lockdown, domestic abuse services have seen an increase in demand for assistance; with the Refuge Charity (2020) reporting a 49\% rise in calls on their national helpline and $417 \%$ increase in traffic to their website. From this data, it becomes obvious that encouraging people to seek solace within the nuclear family unit, whether through UC conditions or COVID-19 restrictions, can 
ensnare more vulnerable individuals in DVA relationships (Barrett and McIntosh, 2015)

\section{Structural abuse}

The presence of sexism and the lack of understanding of DVA partnerships, that the findings confirmed in the design of the UC system, are indicative of wider forms of structural abuse. Despite the government's stated goal of reducing 'welfare dependency', the system ends up punishing recipients for non-compliance rather than encouraging them to seek employment or facilitating their specific needs (DWP, 2011; Dwyer, 2019; Lakhani, 2012). Respondent four stated:

(joint payments have) a huge impact. I mean of course I understand if you are living at the same accommodation, because some of the costs will be less, but they would have a little bit more electricity and the water bill would be double, but you can't cut someone's money in half just because they have a partner, especially for people who have addiction issues, you know it just doesn't work that way, it's not fair on the other person. I think if the government would be more lenient in that, it would make life easier [...] They would be even worse off if they had a joint claim, compared to if they were both on ESA [employment support allowance] having to go to Universal Credit there is already a loss, and then having to go into a couple there is even more loss.

Cuts to public expenditure and social security have exacerbated these issues, with greater consequences on the physical, mental, and financial well-being of claimants (Dwyer, 2019). For couples applying or in receipt of UC, both must agree to have separate Claimant Commitments before payment can be received. In the case of non- 
agreement, if one member of the couple is non-compliant with their work-related requirements it will have negative financial consequences for both individuals (Millar and Bennett, 2016).

\section{Conclusions and ways forward}

The invisibility of women experiencing domestic abuse and violence has been exacerbated by UC welfare reforms, which have entrenched normative patriarchal assumptions of male financial control and female dependency. Alongside this, the pandemic has further increased this precarious position. The findings represent features of structural abuse; abuse resulting from the ways in which society is organised in respect of gender.

There is a clear need for gender critical reform of the UC system and social security and welfare as a whole. The importance of training for staff working across all sectors of social welfare is key to changing perspectives and to removing the veil from a pernicious and continuing problem of gender inequalities throughout all aspects of society. Training using case studies of women experiencing domestic abuse and the narratives of those working at the frontline, such as our respondents, will help ensure the links are made to challenge gender power norms. Also, the deeper and broader recognition of the concept of structural abuse will ensure that policy and practice are viewed through a critical lens that exposes inequalities and challenges us all to make changes to thinking, policy and practice. Recognising these concerns as safeguarding issues is important if we are to make a concerted effort at both systemic change and enhancing the safeguarding system to actively embrace the organisational and 
structural as well as the personal. These reflect concerns that have been brushed aside by recent Governments but represent legitimate areas of safeguarding practice.

\section{References}

Anderson, K. (2019). “Universal Credit, gender and unpaid childcare: Mothers' accounts of the new welfare conditionality regime”, Critical Social Policy, Vol. 40, No.3, pp. 430-449.

Banga, B. (2020). Surviving Two Pandemics: The Impact of COVID-19 Emergency Measures and VAWG on Women's Services, available at https://www.bath.ac.uk/publications/the-impact-of-covid-19-emergency-measuresand-vawg-on-womens-services/attachments/Baljit_Banga_060720.pdf(accessed 21 February 2020).

Barrett, M. and McIntosch, M. (2015). The anti-social family. London: Verso. Bennett, F., (2012). “Universal Credit: overview and gender implications”, In: Kilkey, M., Ramia, G. and Farnsworth, K. (Eds.), Social Policy Review 24: Analysis and Debate in Social Policy, Policy Press, Bristol, pp.15-34.

Bourdieu P (1977). Outline of a Theory of Practice, Cambridge University Press, Cambridge.

Bourdieu, P. (1994). In Other Words, Polity Press, Cambridge.

Campbell, M. (2020). “An increasing risk of family violence during the Covid-19 pandemic: Strengthening community collaborations to save lives". Forensic Science International. Reports. doi: 10.1016/j.fsir.2020.100089 
Cass, B. (1994). “Citizenship, Work, and Welfare: The Dilemma for Australian

Women", Social Politics: International Studies in Gender, State and Society, Vol.1,

No.1, pp.106-124.

Catalá-Miñana, A., Lila, M., Oliver, A., Vivo, J.-M., Galiana, L., \& Gracia, E. (2017).

“Contextual factors related to alcohol abuse among intimate partner violence offenders”. Substance Use \& Misuse. doi.org/10.1080/10826084.2016.1225097

Cheal, D. (1999). “The one and the many: modernity and postmodernity”. In Allen,

G. (Ed.) The Sociology of the Family: A reader, Blackwell, Oxford, pp.56-85.

Cheal, D. (2002). Sociology of Family Life, Palgrave Macmillan, Basingstoke.

Cheetham, M., Moffatt S., Addison,. M. and Wiseman, A. (2019). "Impact of

Universal Credit in North East England: a qualitative study of claimants and support staff.” BMJ Open Vol. 10, No. 1, pp.1-9.

Crenshaw, K. (1989). "Demarginalizing the Intersection of Race and Sex: A Black

Davidge, S., Magnusson, L. and Samuel, M. (2020). The Domestic Abuse Report 2020: The Annual Audit, Women's Aid, London.

Dean, H. (2004). "Popular discourse and the ethical deficiency of 'third way' conceptions of citizenship", Citizenship Studies, Vol. 8 No. 1, pp.65-82.

Department for Work and Pensions (DWP) (2011). Welfare Reform Bill Universal

Credit Equality Impact Assessment, Department for Work and Pensions, London.

Department for Work and Pensions (DWP) (2012). Universal Credit: Evaluation

Framework. Department for Work and Pensions, London.

Dwyer, P. (2004). "Creeping Conditionality in the UK: From Welfare Rights to

Conditional Entitlements?", Canadian Journal of Sociology, Vol.29, No.2, pp.265287. 
Dwyer, P. (2019), Dealing with Welfare Conditionality: Implementation and Effects.

Bristol, Policy Press.

Elgot, J. (2021) Domestic abuse bill: what amendments are peers voting on?

Guardian Online, available at

https://www.theguardian.com/society/2021/mar/15/domestic-abuse-bill-whatamendments-peers-voting-on?CMP=Share iOSApp_Other (accessed 10 April, 2021).

Evans, M.L., Lindauer, M. and Farrell, M.D. (2020). "A pandemic within a pandemic

- Intimate partner violence during Covid-19”, New England Journal of Medicine,

Vol. 383, pp.2302-2304, doi:10.1056/NEJMp2024046.

Fahmy, E. and Williamson, E. (2018). "Poverty and domestic violence and abuse

(DVA) in the UK", Journal of Gender-Based Violence, Vol. 2 No. 3, pp.481-501.

Fahmy, E., Williamson, E. and Pantazis, C. (2016). Evidence and policy review:

Domestic violence and poverty, Joseph Rowntree Foundation, York.

Family and Parenting Institute [FPI] (2011). Families in an Age of Austerity: How

Tax and Benefit Reform Will Affect UK Families, Family and Parenting Institute,

London.

Finch, J. and Summerfield, P. (1999). "Social reconstruction and the emergence of companionate marriage, 1945-59”. In Allen, G. (Ed.) The Sociology of the Family: A reader, Blackwell, Oxford, pp.12-34.

Fletcher, D. and Wright, S. (2018). “A hand up or a slap down? Criminalising benefit claimants in Britain via strategies of surveillance, sanctions and deterrence", Critical Social Policy, Vol. 38, No. 2, pp.324-344.

Foucault, M. (1991) Discipline and Punish: The birth of the prison. Penguin, London. Gaventa, J. (2003). Power after Lukes: A review of the literature, Institute of Development Studies, Brighton. 
Grierson, J. (2021). "Calls to domestic abuse helpline in England up by $60 \%$ over past year". The Guardian Online, $23^{\text {rd }}$ March, available at https://www.theguardian.com/society/2021/mar/23/domestic-abuse-covid-lockdownwomen-refuge?CMP=Share iOSApp_Other (accessed 23 March 2021).

Hantrais, L. and Letablier, M-T. (2021). Comparing and Contrasting the Impact of the COVID-19 Pandemic in the European Union. Routledge, London.

Howard, M. (2018). Universal Credit and Financial Abuse: Exploring the Links Summary and Recommendations, Women's Budgeting Group, London.

Howard, M. and Skipp, A. (2015). Unequal, Trapped and Controlled: Women's Experience of Financial Abuse and Potential Implications for Universal Credit, Women's Aid, London.

Krishnadas, J. and Taha, S. (2020). Domestic violence through the window of the COVID-19 lockdown: a public crisis embodied/exposed in the private/domestic sphere. Journal of Global Faultlines, Vol. 7 No. 1, pp. 46-58.

Lakhani, B. (2012), “Universal Credit: Will it work?”, Local Economy, Vol. 27, No. (5-6), pp.455-464.

Lister, R. (2003). Citizenship: Feminist Perspectives, 2nd edition, Palgrave Macmillan, Basingstoke.

McVey, L., Gurrieri, L. and Tyler, M. (2020). "The structural oppression of women Millar, J. (2018). "Self-responsibility and activation for lone mothers in the United Kingdom”, American Behavioral Scientist, Vol. 63 No. 1, pp.85-99.

Millar, J. and Bennett, F. (2016). "Universal credit: assumptions, contradictions and virtual reality", Social Policy and Society, Vol. 16 No. 2, pp.169-182.

O'Hara, M. (2020). The Shame Game: Overturning the toxic poverty narrative. 
Office for National Statistics (ONS) (2020) Domestic abuse during the coronavirus (COVID-19) pandemic, England and Wales: November 2020, available at https://www.ons.gov.uk/peoplepopulationandcommunity/crimeandjustice/articles/do $\underline{\text { mesticabuseduringthecoronaviruscovid19pandemicenglandandwales/november2020 }}$ (accessed 21 February 2020).

Orloff, A. S. (2009). "Gendering the Comparative Analysis of Welfare States: An Unfinished Agenda", Sociological Theory, 27(3), 317-343.

Parker, J. (2021). "Structural discrimination and abuse: COVID-19 and people in care homes in England and Wales". Journal of Adult Protection, Early Cite doi 10.1108/JAP-12-2020-0050.

Parker, J. and Ashencaen Crabtree, S. (2018). Social Work with Disadvantaged and Marginalised People, SAGE, London.

Pascall, G. (2012). Gender Equality in the Welfare Dtate. Bristol: Policy Press.

Patrick, R. (2014). “Working on Welfare: Findings from a Qualitative Longitudinal Study into the Lived Experiences of Welfare Reform in the UK", Journal of Social Policy, Vol. 43, No.4, pp.705-725.

Penhale, B. and Parker, J. (2020). “Adults at Risk of Abuse”, in Parker, J. and Ashencaen Crabtree, S. (Eds.) Human Growth and Development in Adults Theoretical and practice perspectives Vol. 2, Policy Press, Bristol, pp.269-287.

Pennycook, M. and Whittaker, M. (2012). Conditions Uncertain Assessing the implications of Universal Credit in-work conditionality. The Resolution Centre, London.

Refuge (2020). Refuge reports further increase in demand for its National Domestic Abuse Helpline services during lockdown. Available from: 
https://www.refuge.org.uk/refuge-reports-further-increase-in-demand-for-its-nationaldomestic-abuse-helpline-services-during-lockdown/ [Accessed 7 May 2020]. Roesch, E., Amin, A., Gupta, J. and García-Moreno, C. (2020). "Violence against women during Covid-19 restrictions", British Medical Journal, Vol. 2020, No. 369, m1712, doi: $\underline{10.1136 / \mathrm{bmj} . \mathrm{m} 1712}$.

Sánchez, O.R, Vale, D.B., Rodrigues, L. and Surita, F.G. (2020). "Violence against women during the COVID-19 pandemic: An integrative review", International Journal of Gynaecology \& Obstetrics, doi https://doi.org/10.1002/ijgo.13365. Shaver, S. (2019). "Gender issues in welfare states", In Greve, B. (ed.) Routledge Handbook of the Welfare State, $2^{\text {nd }}$ edition. London, Routledge, pp. 81-91. Smith, J., Flowers, P. and Larkin, M. (2009). Interpretative Phenomenological Analysis: Theory, Method and Research. London, Sage.

Stephenson, M. (2017). Universal Credit: A Briefing from the UK Women's Budget Group. London, Women's Budget Group.

van Gelder, N, Peterman, A, Potts, A, O’Donnell, M, Thompson, K, Shah, N. and Oertelt-Prigione, S. (2020). COVID-19: Reducing the risk of infection might increase the risk of intimate partner violence. Department of Primary and Community Care, Radboud Institute for Health Sciences (RIHS), Radboud University Medical Center, Geert Grooteplein.

Veasey, K. and Parker, J. (2021). "Welfare conditionality, sanctions and homelessness: meanings made by homeless support workers ", Journal of Humanities and Applied Social Sciences, Vol. 3 No. 1, pp.1-17.

Wacquant, L. (2009). Punishing the Poor: The Neoliberal Government of Social Insecurity. Duke University Press, Durham, NC. 
Women's Aid (2020). A Perfect Storm: The impact of the Covid-19 pandemic on domestic abuse survivors and the services supporting them. Women's Aid, Bristol. 